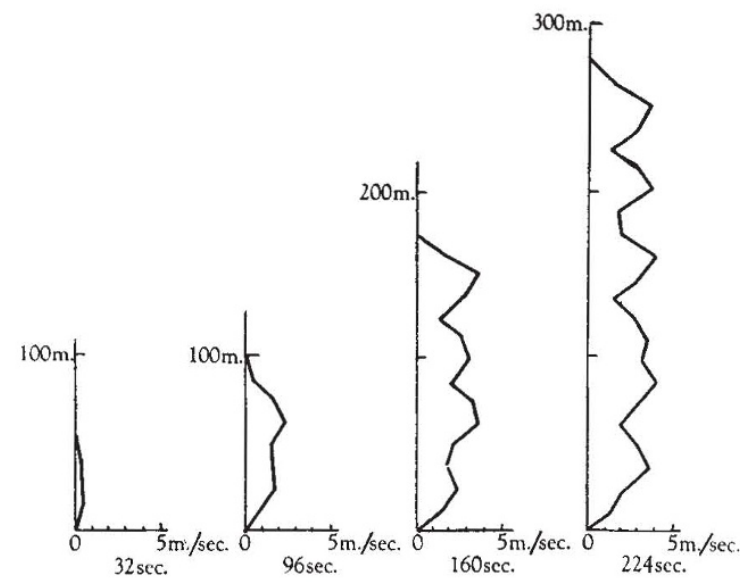

Fig. 4. Development of a thermal. Velocity in m. per sec. Atmoslihere assumed initially static with dry adiabatic lapse-rate. Rate of heating approximately $1^{\circ}$ C. per 3 min. up to $25 \mathrm{~m}$. $1^{\circ} \mathrm{C}$. per 6 min. at $37.5 \mathrm{~m}$, and zero above $50 \mathrm{~m}$.

the known rate of heating that produces them. In both problems the velocity and temperature distributions can be taken as two-dimensional, assuming no variations parallel to a long straight coastline in the case of the sea-breeze, and symmetry about a vertical axis in the case of a convection current. Nevertheless, tho mathematical problem is still very complex, involving frequent integrations of Poisson's equation in two dimensions, a time-consuming process even for an electronic computer. A further simplification was therefore made assuming the form of the vertical distributions of velocity and temperature for the sea-breeze, and the radial distributions for the convection current. These assumptions are not unreasonable when the vorticity distribution is elongated, in this case horizontally for the sea-breeze and vertically for the convection current. The result, after introducing boundary conditions and integrating the equations to include the assumed distributions, is to eliminate one of the space variables, leading to a single partial differential equation to be solved for the surface (or axial) velocity $u$ as a function of distance from the coast (or ground) $x$ and the time $t$. This equation is of the form:

$$
\frac{\partial^{2} u}{\partial t^{2}}+a \frac{\partial^{2}\left(u^{2}\right)}{\partial x \partial t}+b \frac{\partial^{2}\left(u^{3}\right)}{\partial x^{2}}=\mathbf{F}(x, t)
$$

Here $a$ and $b$ are numerical constants with values depending on the assumed profiles of velocity and temperature. $\mathrm{F}(x, t)$ is the horizontal gradient of the heating-rate in the case of the sea-breeze and can be taken as zero everywhere except near the coast. In the case of the convection current, it is the actual heating rate, and this can be taken as zero everywhere except near the ground. The equation is nonlinear since no linearizing assumptions are made in the analysis. Some results of the numerical integration, using the Deuce computer at the University of Glasgow, are shown in Figs. 3 and 4.

The initial development of the sea-breeze near the coast and its subsequent penetration inland are features of the result illustrated by Fig. 3, and the analogous generation of the convection current at the surface and its penetration upwards is illustrated in Fig. 4. In both cases the onset at a point away from the origin is fairly sudden and 'frontal' in nature. Another interesting feature is the series of pulses behind the initial one. There is observational evidence for this occurring after the onset of a sea-breeze, and Mr. Dixon's observations described earlier show this property for a convection current in water. These fluctuations may, however, have been introduced into the computation as a result of truncation errors in the finite-difference approximations used in the integration of the equation. Further computations with different heating-rates show that smaller currents develop more rapidly than larger oncs, as one observes on a typical convection day when the larger clouds usually develop during the late morning or afternoon.

The symposium ended with a general discussion. Dr. Ludlam's dynamical picture of a thunderstorm was discussed at some length and it became obvious that here was a useful field of study for the dynamical meteorologist, for no mathematical theory which can account for even the broadest features of these storms at present exists.

R. P. Pearce

\title{
SAFETY OF FACTORY WORKERS
}

T THE annual report of the Chief Inspector of Factories for 1959 reports a further decline in the number of fatal accidents, from 665 in 1958 to 598 in 1959 , the lowest figures recorded this century*. While this figure continues the consistent downward trend in fatalities from the 828 in 1951 , the downward trend in total accidents of the previous three years was checked, and the number of reported accidents rose from 167,697 in 1958 to 174,071 , in spite of increased activities in the field of accident prevention, although it may be partly explained by the increase in the number of people employed and hours worked. The Chief Inspector, however, finds the increase in the number of accidents to young

* Ministry of Labour and National Service. Annual Report of the Chicf Inspector of Factories for the year 1959. Pp. 128. (Cmnd. 1107.) (London: H.M. Stationery Office.) $7 s$. net. persons disturbing, and one of two chapters in the report dealing with subjects of interest without being necessarily restricted to the events of the year deals with the prevention of accidents to young persons. This has been discussed in Nature of November 5 , p. 460 ; the other special chapter deals with designing machinery for safe operation. Besides directing attention to some of the more important safety principles, which, it is suggested, machine manufacturers should bear in mind, it urges that every opportunity should be taken to bring such eonsiderations before the professional, research and teaching authorities concerned, and that industry as the user should insist on getting premises, plant and equipment with safety 'built in' by the suppliers.

As a result of a considerable number of changes made in the analysis and classification of information 
about reported accidents, it should be possible to make greater use of the information already provided in the accident reports, and in addition to tables analysing accidents by industry, causation and process, there is included for the first time a table giving accident incidence rates for most of the industries under the manufacturing headings of the Standard Industrial Classification, as revised in 1958. In a number of industries, research associations and other bodies have continued to examine important problems of health and safety, such as dust and fumes and dangerous machinery, and the Chief Inspector believes that other industries could, with advantage, make wider use of their research associations in helping to solve their own special problems in this field. During the year, thirteen inspectors were appointed to the general inspectorate and at the end of the year eight more were awaiting appointment. Twelve inspectors were recruited to the specialist branches, and at the end of the year 409 inspectors of all grades were in posts, but there were twenty-four vacancies in the general inspectorate, one each in the Medical and the Electrical, and seven in the Chemical Branches.

At the end of 1959 there were 222,117 registered factories in Britain, compared with 223,085 in 1958, the decrease being almost entirely in the number of factories without mechanical power. An analysis in March showed that about one quarter of the factory population work in factories employing more than 1,000 people, but only four factories in every thousand are of this size, and on the other hand two-thirds of the number of factories employ fewer than ten people, but less than a thirtieth of the factory population. More than 26 per cent of reported accidents occurred in 'handling goods', $15 \cdot 1$ per cent were caused by falls of persons, and falls of all sorts accounted for 91 fatal accidents in factories, or 26 per cent of all fatalities. A chapter in the report re. viewing the year mentions a number of industrial developments which have promoted greater safety in industry.

\section{PHYTOGEOGRAPHY OF THE AUSTRALIAN REGION}

\begin{abstract}
$\mathrm{D}$ R. NANCY T. BURBIDGE has recently published a comprehensive account and analysis of the principal floristic regions of the vast Australian area, and of selected areas within it of special interest*; she has discussed the composition of the flora in relation to geological and geographical factors, and in a map of considerable interest she has indicated the probable paths of migration, chiefly by way of Sumatra, the Philippines and New Guinea, but including movements within the region, that have contributed to the contemporary phanerogamic vegetation. The phytogeographical region is regarded as including Australia and Tasmania, and can be divided into the tropical zone in the north and east, the temperate zone in the south and east, and the 'Eremran' zone in the arid centre. While the demarcation of these zones is closely related to contemporary climatic conditions, the respective floras also show the results of selection by former climatic and geographieal conditions.
\end{abstract}

Dr. Burbidge reports that although the flora of the South-West Province shows the highest proportion of endemism, there is a close relationship with the flora of the eastern part of the temperate zone. The Province, in fact, is not 'the 'cradle' of the autochthonous elements of the Australian flora though it is apparently an asylum for many relict forms".

At the generic level the Tasmanian flora is not highly endemic, but it shows certain affinities with the flora of Malaysia and with genera found along the Malaysia-New Zealand are or genera also occurring in South America. Some of the genera are unknown on the mainland, others are known from Australian Tertiary deposits. It appears that the Tasmanian flora includes relics from early Tertiary floras, survivors from the cold-climate regimes of the Pleistocene, and Australian elements which have

* Australian J. Bot., 8, 75 (1960). mingled with the flora during periods of land continuity.

The high rainfall habitats of north-east Queensland are remarkable for the large number of families, genera, and species which are restricted to them, that is, within the Australian region. Thus, many genera have only a single representative which may also occur in Malaysia. Dr. Burbidge considers that some of these may be recent arrivals while others, known as fossils from southern deposits, have a more restricted distribution than in the past. While the close affinity with the flora of New Guinea is noted, Dr. Burbidge points out that there are certain affinities with the floras of New Caledonia and New Zealand which may be independent of those of other parts of the Australian region.

The composition of the Australian flore is primarily attributable to climatic selection within the region and from the biotypes which have become available as a result of migration-migration by communities rather than by chance dispersel of individuals being regarded as a major factor.

The study of Tertiary floras, though not extensive, indicates an affinity with the flora of South America which is "contrasted with the marked lack of data suggesting a similarly increased relationship with southern Africa. The relationship between fossil and modern representatives of such genera as Podocarpus, Dacrydium, and Nothofagus suggests that there has been a northward migration or a withdrawal to warmer latitudes since the Tertiary. All the main elements of the present-day flora are represented in the Tertiary assemblages. If current views on the 'Malaysian' or 'tropical' nature of some affinities and the 'Antarctic' nature of others be accepted then there is no indication that the major migration into the Australian Region came from one particular direction". 